INDEPENDENT JOURNAL OF MANAGEMENT \& PRODUCTION (IJM\&P)

http://Www.ijmp.jor.br

V. 10, n. 5, September-October 2019

ISSN: 2236-269X

DOI: $10.14807 /$ ijmp.v10i5.890

\title{
PREVENTIVE ANTICRISIS STRATEGY FOR DEVELOPMENT OF INDUSTRIAL ENTERPRISE
}

\author{
Hanna Tarasova \\ Kiev National University of Technology and Design, Ukraine \\ E-mail: tarasova.ganna@gmail.com
}

Sergey Zaharov

Metinvest PromServis, Ukraine

E-mail: sergey.v.zakharov@metinvestholding.com

Mykhaylo Vereskun

Priazovsky State Technical University, Ukraine

E-mail: vereskun.m.v@ukr.net

Valeriia Kolosok

Priazovsky State Technical University, Ukraine

E-mail: kolosok.v.m@gmail.com

Submission: $10 / 08 / 2018$

Accept: 11/28/2018

\section{ABSTRACT}

It is established that under anticipatory management of industrial enterprises it is expedient to prevent the development of anticrisis strategies for counteracting the most probable crises for an industrial enterprise. At the same time, the main question is to determine when it is necessary to intensify these preventive anticrisis development strategies. To solve this problem, a scientific and methodical approach has been developed to intensify anticrisis strategies for the development of an industrial enterprise on the basis of weak signals, based on the use of a model for estimating the proximity of an industrial enterprise to a crisis state, and which provides for the preventive adaptation of an industrial enterprise to abrupt changes in the environment or changes in the development trajectory enterprises. It makes possible to assess the stability of the trajectory of development of the industrial enterprise at a specific time, and, accordingly, to carry out anticipatory management of the development of the industrial enterprise. 
INDEPENDENT JOURNAL OF MANAGEMENT \& PRODUCTION (IJM\&P)

http://www.ijmp.jor.br

V. 10, n. 5, September-October 2019

ISSN: 2236-269X

DOI: 10.14807/ijmp.v10i5.890

Keywords: development, crisis management strategies, industrial enterprise

\section{INTRODUCTION}

When developing the strategy of anticipatory management, the development of an industrial enterprise, one of the most effective approaches to responding to crisis phenomena is the use of preventive or passive adaptation, that is, the activation of existing development strategies, which at one time was developed to overcome typical crises. Such an adaptation suggests that in forming a general strategy for the development of an enterprise, account should be taken of the possibility of occurrence of the most typical and probable crises, and planned methods for their overcoming (HROZNYI, et. al, 2018).

Among the main difficulties that arise in this case, one should note the need to identify the crisis in a timely manner. It has been established that the most promising approach for timely detection of crises in an unstable economic environment is the use of methods of economic dynamics, namely analysis of weak signals. The analysis of weak signals is an integral part of the anticipatory management of the enterprise, which can reveal early signs of changing the trajectory of the environment or the enterprise itself.

The purpose of the paper is to timely identify crises in an unstable economic environment, taking into account the analysis of methods for calculating and assessing weak signals indicating that the crisis is approaching. The paper offers a comparison of plans for the development of industrial enterprises with typical crises; identifying crisis markers, for which it is necessary to evaluate weak signals, assess the potential and forces of the expected crisis from the point of view of the development of an industrial enterprise; justification of the decision of the management to strengthen the anti-crisis strategy for managing the development of the industrial enterprise. The analysis will be conducted for the Ukrainian industrial company.

The following sections of the paper will present definitions of typical crisis phenomena through formalized and structured methods for calculating and assessing weak signals, as well as a model for assessing the proximity of an industrial enterprise to a crisis situation, which is then evaluated for the Ukrainian industrial company.

\section{LITERATURE REVIEW}


Crisis management is the process by which an organization deals with a disruptive and unexpected event that threatens to harm the organization or its stakeholders (BUNDY et. al, 2017).

Crisis management techniques include a series of further steps, ie the reaction of an industrial enterprise to prevent, mitigate or overcome various types of crisis.

Approaches to effective crisis management are based on the following aspects:

- adequate perception of the crisis.

- the classification of the indicators of the crisis life cycle scenarios and the corresponding response mechanisms.

- communication processes for responding to the development of emergency management scenarios (GROH, 2014).

Research shows that organizational contributory factors affect the tendency of executives to adopt an effective "crisis as opportunity" development (JAMES, 2008).

Among the studies of crisis states, an early warning based on weak signals is particularly highlighted in the management of the development of industrial enterprises.

The system has to face the dilemma of warning signals (CEVOLINI, 2016).

The system must be able to detect symptoms and weak signals outside and in the company and sent to a competent employee who will carry out an analysis of the cause of this state and confirm or deny negative development that might lead to a crisis situation (ZUZAK, 2001, 2017).

Classification of weak signals of an industrial enterprise, which are distributed by types of enterprise activities: production, scientific and technical preparation of production, financial and economic, marketing, logistics, social and personnel and foreign-economic. However, instruments for quantitative measurement of these signals and for their formal analysis have not been proposed (MELNYK; ADAMOV, 2009).

Main problem of early warning systems using weak signals is the impossibility of their use in practice because they do not distinguish weak signals from background noise as well as the absence of descriptions of characteristic features weak signals 
INDEPENDENT JOURNAL OF MANAGEMENT \& PRODUCTION (IJM\&P)

http://Www.ijmp.jor.br

V. 10, n. 5, September-October 2019

ISSN: 2236-269X

DOI: 10.14807/ijmp.v10i5.890

(RUBANOV, 2013). He proposes to use a control system from three levels to solve this problem, which consists of the preliminary, current and final control. But it does not pay sufficient attention to the mathematical justification of the approaches to isolating noise from signals and what particular features are the weak signals typical of an industrial enterprise.

Also, the problem of the diagnosis of weak signals is devoted to the study of Kuzmin and Adamov (2013), who offer to diagnose weak signals, taking into account the type of enterprise. It detects signals that have a potential impact on the company, determines the level of entropy of these signals, constructs a tree of consequences for the enterprise for each signal, evaluates the opportunities and threats for the enterprise using the Monte Carlo method and formulates conclusions about the quantitative effect on the results of the operation of the enterprise. Despite the promise of this approach, it should be noted that beyond the scope of the study remains the question of responding to the company's potential threats, as evidenced by the weak signals that were diagnosed.

Mechanism of management of economic safety of the enterprise by means of weak signals, analyzed the peculiarities of weak signals of machine-building enterprises, which testify to economic crises. To isolate weak signals from noise (SHANKRET; KARAIM, 2015) was proposed to use internal standards on the level of economic security in the context of the main functional components and the information base of experience. But it does not describe exactly which formalized methods for calculating signal and noise criteria should be used.

In contrast to the previous approach, proposed a formalized approach to detecting a weak signal, which assumes that it is necessary to calculate the integrated indicators of the influence of external factors on the enterprise and to find the difference between the planned and actual values of these integrated indicators (ZMOTS, 2012; SHIRYAEV, 2016).

If this difference is greater than the established limit, then a weak signal is considered to be detected. But it should be noted that the proposed approach to the analysis of weak signals does not take into account the trajectories of the environment and the enterprise itself. Because of this, the weak signal may not have a significant impact on the emergence of crises, because according to the theory of economic 
INDEPENDENT JOURNAL OF MANAGEMENT \& PRODUCTION (IJM\&P)

http://Www.ijmp.jor.br

V. 10, n. 5, September-October 2019

ISSN: 2236-269X

DOI: 10.14807/ijmp.v10i5.890

dynamics, weak signals are important when the economic system is near to the point of bifurcation.

Dyaduk (2015) suggests identifying threats to the enterprise based on the weak signals coming from the environment in the following areas: consumers, resource support, affiliated and supporting industries, the competitive environment, government structures, and occasional phenomena. But it should be noted that most of the proposed signals are traditional and are widely used in the management of the enterprise. For example, it is a negative dynamics of commodity turnover, falling stock of own shares, rising prices, and so on. Negative values of these signals indicate the existing problems and the already existing crisis, and not the possibility of other trajectories at the point of bifurcation of the economic system.

The modeling of the production planning control system for weak signals, the main factor of which is the analysis of regulatory balances in the warehouse, was introduced by Petrova, Kovalevskaya and Musienko (2011). This makes it possible to detect inconsistency of planned and actual indicators and timely adjust the production program. The main disadvantage of this approach is to ignore the need to detect weak signals of the environment, which is often the source of the crisis, as well as the inability of the proposed model to be used at the strategic level in developing a strategy for the development of an industrial enterprise.

On the whole, it can be concluded that traditional approaches to the identification of typical crisis phenomena are mainly focused on comparing planned and actual indicators or, at all, with no formalized and structured methods for calculating and assessing weak signals indicating that the crisis is approaching. Therefore, in an anticipatory management of the development of an industrial enterprise, there is a need to develop approaches that would address such tasks:

- comparison of plans for the development of industrial enterprises with typical crises;

- identify the markers of the crisis, for which it is necessary to evaluate the weak signals

- assessment of the potential and strength of the expected crisis in terms of the development of an industrial enterprise; 
INDEPENDENT JOURNAL OF MANAGEMENT \& PRODUCTION (IJM\&P)

http://Www.ijmp.jor.br

V. 10, n. 5, September-October 2019

ISSN: 2236-269X

DOI: 10.14807/ijmp.v10i5.890

- the substantiation of the managerial decision to intensify the anticrisis strategy for managing the development of the industrial enterprise.

\section{METODOLOGY}

The proposed sequence, the main measures to intensify the anticrisis strategies for the development of an industrial enterprise on the basis of weak signals and the results of their implementation is shown in Figure 1.

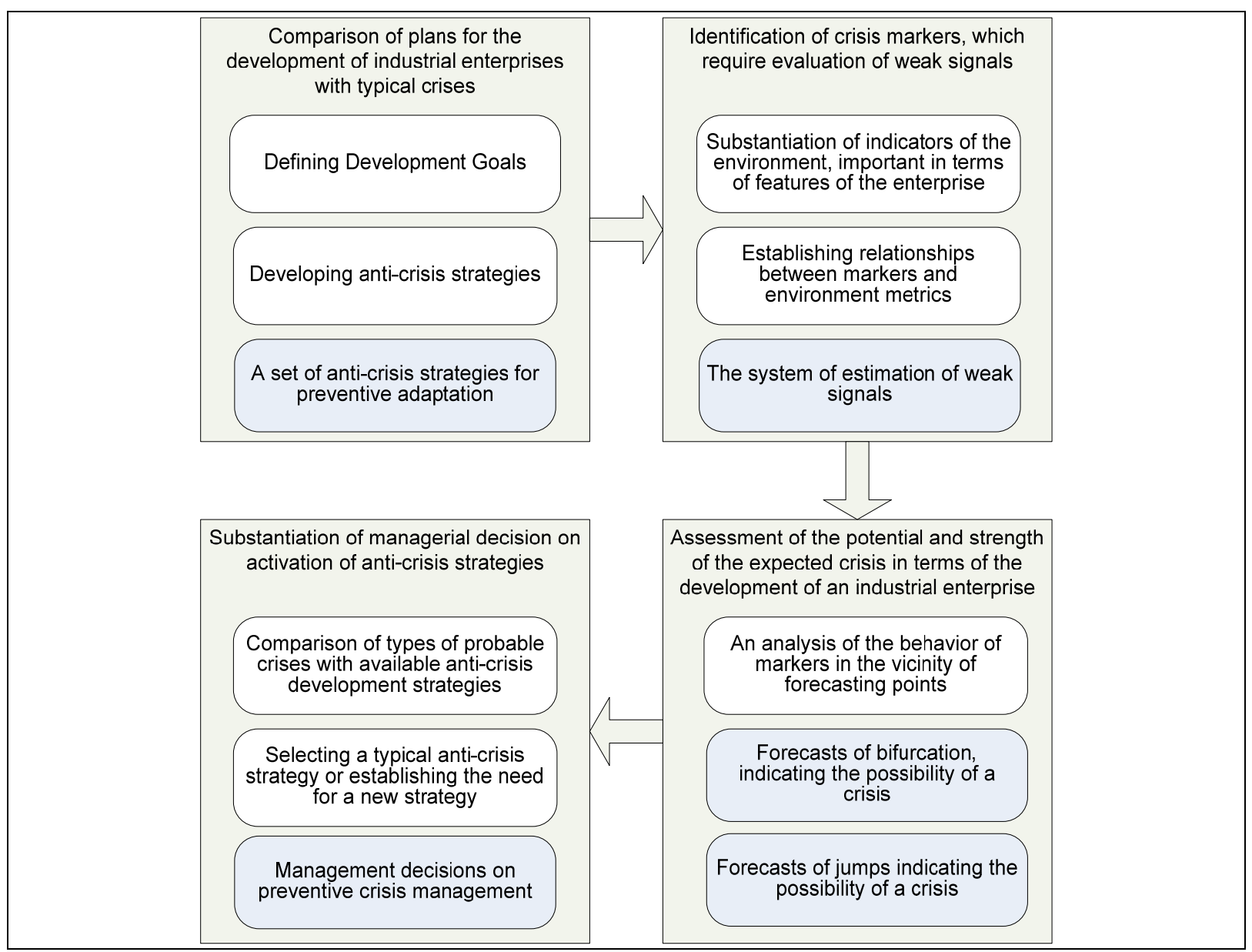

Figure 1: Management of activation of anticrisis strategies of industrial enterprise development on the basis of weak signals

Source: own research

From the point of view of intensification of anticrisis strategies for the development of an industrial enterprise, possible crises can be classified according to the type of jump, sources of origin and consequences.

The economic crisis is always out of range, in which the company feels comfortable. This output can be slow or fast. With a slow exit beyond the range of effective functioning, the change in key performance indicators of the enterprise is gradually and deterioration can be provided by the usual methods of forecasting. A 
INDEPENDENT JOURNAL OF MANAGEMENT \& PRODUCTION (IJM\&P)

http://www.ijmp.jor.br

V. 10, n. 5, September-October 2019

ISSN: 2236-269X

DOI: 10.14807/ijmp.v10i5.890

quick exit from the range of effective operation of an industrial enterprise is either an immediate change in the key indicators of the enterprise to large or even dual development paths (bifurcation), when it is difficult to establish in advance what kind of trajectory will be chosen by the economic system.

By sources it is suggested to distinguish between internal and external crises. Internal crises are due to life cycles of the industrial enterprise, as well as internal management crises, such as personnel force majeure. External crises are the consequences of changes in the economic environment of an industrial enterprise, such as:

- change of legislative restrictions, for example, currency regulation, tax rates, obtaining permits for business activity, etc.;

- moving equilibrium in world markets or local markets of a country where an industrial company is a party (markets refer to both commodity and financial markets and the labor market);

- change in the stage of the life cycle of the industry to which the industrial enterprise belongs.

Among the consequences of crisis phenomena from the point of view of the industrial enterprise, the following are the main ones:

- decrease in the quantity of sold products;

- decrease in the price of sold products;

- increase in production costs;

- increase in other expenses.

After forming a hierarchy of typical crisis situations that can affect an industrial enterprise, it is possible to determine which weak signals indicate that these crisis situations are approaching, and which typical anticrisis strategies for the development of an industrial enterprise should be intensified in order to overcome the consequences of the crisis in a timely manner. Typical anticrisis strategies for the development of an industrial enterprise are as follows (ANALOI; KARAMI, 2012; PEARCE; ROBINSON, 2013; THOMPSON; STRICKLAND, 2013): 
- strengthening of market positions due to the development of the marketing network, advertising, the absorption of competitors, etc;

- the capture of new markets for products manufactured by an industrial enterprise;

- improvement of products manufactured by an industrial enterprise (change of technologies, development of new products, modernization of production capacities, etc);

- integrated development strategy through reverse vertical integration, which involves the acquisition of existing ones or the creation of their own companies to provide raw materials, services;

Integrated development strategy through frontal vertical integration, which involves the purchase of existing ones or the creation of their own companies for work with consumers (transport companies, service centers, trading networks, etc);

- implementation of centered diversification (development of production of new products without changing technologies and markets);

- implementation of horizontal diversification (development of production of new products using new technologies in the old markets);

- the implementation of conglomerate diversification (access to new markets through the development of production of new products, which is not connected with the old one);

- redeeming the crisis by reducing the structural units that are not essential for generating profits;

- repaid the crisis by reducing costs by reducing non-core expenditures, deteriorating quality, cutting premiums and wages.

\section{THE MAIN PROVISIONS}

Consequently, the main task of anticipatory management with preventive adaptation is the timely detection of the crisis. You need to assess how close the indicators are characterizing the industrial enterprise to the points of bifurcation or points at which rapid changes are possible. For this purpose, it is assumed that the trajectory of indicators of the development of an industrial enterprise, which are also 
markers of a crisis state, can be described by functions of several arguments. Several indicators can be set for a Ukrainian industrial company, the rapid deterioration of which is considered a marker of a crisis state:

- net profit;

- sales volume;

- market share;

- profitability.

In general, the dependence of the marker of the crisis state on other indicators has the form:

$$
N^{k}(t)=f^{k}\left(P_{1}^{k}(t), \ldots, P_{S^{k}}^{k}(t)\right),
$$

where $N^{k}(t)$ - the value of the $\mathrm{k}$-th marker of the crisis state at the time $\mathrm{t}$;

$f^{k}()$ - a function that reflects the relationship between the k-th marker of the crisis state and the indicators of the external and internal environment;

$$
P_{1}^{k}(t), \ldots, P_{S^{k}}^{k}(t) \text { - the value of the indicators of the external and internal }
$$
environment at the time $\mathrm{t}$;

$S^{k}-$ the number of internal and external environment indicators for the k-th marker.

To assess the risk of a crisis state, it is necessary to determine whether the schedule of the function $f^{k}()$ have significant jumps with minor variations of arguments. To do this, you need to calculate the partial derivative functions that reflect how the marker changes at a point, provided that the increment of the argument goes to zero. If the private derivative at the point exceeds the limit, then the system is under threat of a crisis, because the slightest change in the argument can lead to a significant change in the marker of the crisis state. An appropriate model is proposed for assessing the degree of threat of an outbreak of a crisis for an industrial enterprise:

To assess the risk of a crisis state, it is necessary to determine whether the function $f^{k}()$ can have significant jumps with minor variations in the arguments. You 
DOI: 10.14807/ijmp.v10i5.890

need to calculate the partial derivative functions that reflect how the marker changes at a point, provided that the increment of the argument goes to zero. If the private derivative at the point exceeds the limit, then the system is under threat of a crisis, because the slightest change in the argument can lead to a significant change in the marker of the crisis state. An appropriate model is proposed for assessing the degree of threat of an outbreak of a crisis for an industrial enterprise:

$$
\begin{aligned}
& R_{s}^{k}=\frac{d_{P_{s}^{k}} f^{k}}{d P_{s}^{k}}, \\
& L_{s}^{k}=\left\{\begin{array}{l}
M^{k}-3 \sigma^{k} \geq R_{s}^{k}\left(t^{\prime}\right) \wedge M^{k}+3 \sigma^{k} \leq R_{s}^{k}\left(t^{\prime}\right) \Rightarrow 0 \\
M^{k}-3 \sigma^{k}<R_{s}^{k}\left(t^{\prime}\right) \vee M^{k}+3 \sigma^{k}>R_{s}^{k}\left(t^{\prime}\right) \Rightarrow 1
\end{array}\right. \\
& L^{k}=\frac{\sum_{s} L_{s}^{k}}{S^{k}},
\end{aligned}
$$

where $R_{s}^{k}$ - private derivative k-th marker of a crisis state by variable $P_{s}^{k}$;

$d_{P_{s}^{k}} f^{k}$ - private differential function $f^{k}\left(P_{1}^{k}(t), \ldots, P_{S^{k}}^{k}(t)\right)$ for variable $P_{s}^{k}$;

$d P_{s}^{k}-$ infinitely small increment of the variable $P_{s}^{k}$;

$L_{s}^{k}-$ the result of the assessment of the threat of crisis by the indicator $P_{s}^{k}$;

$M^{k}$ - mathematical expectation of change k-th a marker of a crisis state in crisis-free conditions of the functioning of an industrial enterprise;

$\sigma^{k}$ - mean square deviation $\mathrm{k}$-th a marker of a crisis state in crisis-free conditions of the functioning of an industrial enterprise;

$R_{s}^{k}\left(t^{\prime}\right)$ - the value of a private derivative k-th marker of a crisis state by variable $P_{s}^{k}$ at the point $t^{\prime}$;

$L^{k}-$ the final result of the threat assessment for the k-th marker; 
$S^{k}$ - the number of internal and external environment indicators for the k-th marker.

The final result of the assessment of the crisis of the threat for the k-th marker is in the range from zero to one, where zero corresponds to the absence of the possibility of a crisis at the point at the time $t^{\prime}$, and the unit is the most likely, at which the least deterioration of any of the indicators having an effect on marker, can lead to a crisis state.

The indicated model for estimating the proximity of an industrial enterprise to a crisis state is based on the assumption that, in normal operation, the growth rates of an industrial enterprise have a normal distribution, so they are subject to the rule of three sigmas (LEBEDEVA, 2007; SHIRYAEV, 2016).

The output growth of a marker of a crisis state beyond the range of three sigma (three mean square deviations) indicates that at the time of the time being investigated, the onset of a crisis may occur. If the history of the operation of the industrial enterprise does not have a sufficient lifetime to calculate the mathematical expectation and the mean square deviation, or the growth of the state of the markers has a distribution different from the normal, an expert assessment of the maximum permissible deviation based on generally accepted norms or conclusions can be used as a criterion , taking into account the features of a particular industrial enterprise. Then the assessment of the threat of the crisis by the indicator $P_{s}^{k}$ is carried out according to the formula:

$$
L_{s}^{k}=\left\{\begin{array}{l}
E^{k} \geq R_{s}^{k}\left(t^{\prime}\right) \wedge E^{k} \leq R_{s}^{k}\left(t^{\prime}\right) \Rightarrow 0 \\
E^{k}<R_{s}^{k}\left(t^{\prime}\right) \vee E^{k}>R_{s}^{k}\left(t^{\prime}\right) \Rightarrow 1
\end{array},\right.
$$

where $L_{s}^{k}$ - the result of an assessment of the crisis threat for the indicator $P_{s}^{k}$; $E^{k}$ - expert assessment or norm of the maximum allowable deviation of the indicator $N^{k}(t)$ in crisis-free conditions, the functioning of an industrial enterprise;

$$
R_{s}^{k}\left(t^{\prime}\right) \text { - the value of the private derivative of the k-th marker of the crisis state }
$$
by the variable $P_{s}^{k}$ at the point $t^{\prime}$. 
INDEPENDENT JOURNAL OF MANAGEMENT \& PRODUCTION (IJM\&P)

http://Www.ijmp.jor.br

V. 10, n. 5, September-October 2019

ISSN: 2236-269X

DOI: 10.14807/ijmp.v10i5.890

The moment of time $t^{\prime}$ for which the investigation of the probability of a crisis can be as present, if the probability of a crisis is calculated for the current time, and in the future. In the latter case, the values of the external and internal environment for the calculation of private derivatives are predictable.

The specific dependencies of markers on external and internal indicators are determined by the characteristics of an industrial enterprise. Moreover, it is important to emphasize that these dependencies are not necessarily direct calculation formulas. In the aspect of forecasting the crisis state of an industrial enterprise, it is important to analyze such trajectories as an enterprise, in which minor changes in factors can lead to significant changes in the results of the enterprise. indicators Thus, for example, at a certain level of tax burden there is a general decline in sales due to a decline in economic activity, in addition, this indicator has a direct impact on net profit. The main relationship between the indicators of the external and internal environment and the marker indicators, which was chosen as the basis for building a system for assessing the probability of a crisis, is shown in Table 1.

Table 1: Dependence between markers and external and internal forecast indicators

\begin{tabular}{|c|c|}
\hline $\begin{array}{c}\text { Typical predictive indicators that affect } \\
\text { markers }\end{array}$ & $\begin{array}{c}\text { Indicators whose change is a marker of a } \\
\text { crisis state }\end{array}$ \\
\hline Level of tax burden & Net profit, sales volume \\
\hline Technological state of production & Profitability, market share \\
\hline Uniqueness of production & Market share, sales volume \\
\hline Gross expenditures & Net profit \\
\hline Gross revenues & Net profit \\
\hline The level of competition in the market & Market share, net profit, sales volume \\
\hline Relations with external contractors & Net profit, sales volume \\
\hline Development of related industries & Sales volume \\
\hline Comparative product quality & Market share, net profit, sales volume \\
\hline Development of a marketing network & Market share \\
\hline Comparative price of products & Market share, sales volume \\
\hline The amount of fixed costs & Net profit, profitability \\
\hline Volume of variable costs & Profitability \\
\hline Operating income & Profitability \\
\hline Other income & Profitability \\
\hline Damage percentage & Market share, profitability \\
\hline Staff qualification & Market share, profitability \\
\hline
\end{tabular}

Depending on the characteristics of the industrial enterprise, additional marker indices or indicators of the external or internal environment can be added. In addition to the usual dependence of marker indicators on indicators of the external or internal environment, the company can also be analyzed as a dynamic economic system. This approach is appropriate in the case of inertia in marker indices, when the token value 
DOI: 10.14807/ijmp.v10i5.890

also depends on its value at a previous time point. A dynamic system can be described using differential or differential equations (ARNOLD; APHRAIMOVICH; ILYASHENKO; SHILNIKOV, 1986; ARNOLD, 2016; TSARKOV, 2007). In general, the differential equation for describing the marker of the crisis of an industrial enterprise has the form:

$$
\frac{d N^{k}(t)}{d t}=f^{k}\left(N^{k}(t-1), P_{1}^{k}(t), \ldots, P_{S^{k}}^{k}(t)\right),
$$

where $N^{k}(t)$ - the value of the k-th marker of the crisis state at time $\mathrm{t}$;

$f^{k}()$ - a function that reflects the relationship between the k-th marker of the crisis state and the indicators of the external and internal environment;

$$
P_{1}^{k}(t), \ldots, P_{S^{k}}^{k}(t) \text { - value of indices of external and internal environment at time }
$$
$\mathrm{t}$;

$S^{k}$ - the number of internal and external environment indicators for the k-th marker.

For dynamic economic systems, S-shaped types of dependencies are typical. Therefore, it is proposed as a general form for the analysis of processes of an industrial enterprise that can lead to a crisis, to use the differential equation of Ferghilst (ARNOLD, 2016; TSARKOV, 2007):

$$
\frac{d N^{k}(t)}{d t}=r N^{k}(t-1)\left(1-\frac{N^{k}(t-1)}{N^{l i m}}\right),
$$

$$
\text { where } \frac{d N^{k}(t)}{d t}-\text { the derivative of the k-th marker of the crisis state for a variable }
$$

$\mathrm{t}$;

$r$ - the rate of change of the $\mathrm{k}$-th marker of a crisis state;

$N^{k}(t-1)$ - the value of the $\mathrm{k}$-th marker of the crisis state at the time $\mathrm{t}-1$;

$N^{\lim }$ - the maximum possible value of the k-th marker of the crisis state. 
Equation (7) can be used for indicators that have a tendency to selfdevelopment, when the influence of external factors is minimal. For example, for an industrial company that is a monopolist and entered the market with a revolutionary new product, such an equation may describe sales if information about this product is carried out by the method of network marketing, from user to user. In this case, the maximum possible value $N^{\text {lim }}$ this is the total number of consumers. Equation (7) can also be used not only for markers, but also for studying the points of bifurcation of environmental factors, such as the market capacity for consumer goods.

\section{CONCLUSIONS}

It is established that in the conditions of a modern economy, which is characterized by regular crises, an industrial enterprise for development needs to have pre-designed crisis-management strategies for timely response to typical crises. The main problem here is the need to identify the crisis in a timely manner. The most promising approach for timely detection of crises in an unstable economic environment is the analysis of weak signals.

It is concluded that traditional approaches to the identification of typical crisis phenomena are mainly devoted to comparing planned and actual indicators or do not have formalized and structured methods for calculating and assessing weak signals indicating that the crisis is approaching. Therefore, in an anticipatory management of the development of an industrial enterprise, there is a need to develop approaches that would ensure: comparison of plans for the development of industrial enterprises with typical crises; identifying the markers of the crisis, for which it is necessary to evaluate the weak signals, assess the potential and strength of the expected crisis in terms of the development of the industrial enterprise; the substantiation of the managerial decision to intensify the anticrisis strategy for managing the development of the industrial enterprise.

It is proposed to consider the economic crisis situation as a way out of the range in which the enterprise feels comfortable. With a slow exit beyond the range of effective functioning, the change in key performance indicators of the enterprise is gradually and deterioration can be provided by the usual methods of forecasting. A quick exit from the range of effective operation of an industrial enterprise is either an immediate 
INDEPENDENT JOURNAL OF MANAGEMENT \& PRODUCTION (IJM\&P)

http://Www.ijmp.jor.br

V. 10, n. 5, September-October 2019

ISSN: 2236-269X

DOI: 10.14807/ijmp.v10i5.890

change in the key indicators of the enterprise to large or even dual development paths (bifurcation), when it is difficult to establish in advance what kind of trajectory will be chosen by the economic system.

The model of estimation of the proximity of the industrial enterprise to the crisis situation through the evaluation of weak signals is developed, which makes it possible to assess the stability of the trajectory of development of the industrial enterprise at a specific time, and, accordingly, to carry out anticipatory management of the development of the industrial enterprise. The simulation results confirmed the performance of the model, as well as its adequacy.

At the same time, it is worthwhile to start a discussion on mechanisms of preventive counteraction to the primary symptoms of crisis conditions of industrial enterprises under uncertainty. Important is the fact that the trajectory of the development of an industrial enterprise should remain in the controlled range of deviations.

\section{REFERENCES}

ANALOI, F.; KARAMI, A. (2012) Strategic Management of Small and Medium Enterprises, Moscow: UNITI, 400.

ARNOLD, V. I. (2016) Theory of catastrophes, M.: Lenand, 134.

ARNOLD, V. I.; APHRAIMOVICH, V. S.; ILYASHENKO, YU. S. (1986) Theory of bifurcations, M.: VINITI, 218.

BUNDY, J.; PFARRER, M. D.; SHORT, C. E.; COOMBS, W. T. (2017). Crises and crisis management: Integration, interpretation, and research development. Journal of Management, n. 43, p. 1661-1692.

CEVOLINI, A. (2016) The Strongness of Weak Signals: Self-reference and Paradox in Anticipatory Systems. European Journal of Futures Research, v. 4, n. 4, p. 1-13.

DYADYUK, M. A. (2015) Management of weak signals in the system of adaptive management of trade enterprises. Economic strategy and prospects of development of the sphere of trade and services, n. 2, p. 74-83.

$\mathrm{GROH}$, M. (2014) Strategic Management in Times of Crisis. American Journal of Economics and Business Administration, v. 6, n. 2, p. 49-57.

HROZNYI, I.; KUZMAK, O.; KUZMAK, O.; RUSINOVA O. (2018) Modeling management of diversification of foreign economic interactions. Problems and Perspectives in Management. v. 16, n. 1, p. 155-165. http://dx.doi.org/10.21511/ppm.16(1).2018.15

JAMES, E.; JAMES, E. H. (2008) Toward an Understanding of Executives See Crisis as Opportunity, The Journal of Applied Behavioral Science, v. 44, n. 1, p. 94-115. 
KUZMIN, O. E.; ADAMOV, M. E. (2013) Method of perspective diagnostics of weak signals of potential phenomena by types of enterprise activity. Business Inform, n. 2, p. 69-74

LEBEDEVA, T. V. (2007) Statistical methods of forecasting in economics, Orenburg: OGU, 174.

MELNYK, O. G.; ADAMOV, M. E. (2013) Anticipatory management of enterprises on the basis of weak signals. Current problems of the economy, n. 1, p. 32-41.

PETROVA, R. V.; KOVALEVSKAYA, A. V.; MUSIENKO V. O. (2011) Economical and mathematical model of control of production planning by weak signals. Bulletin of social and economic research, v. 41, n. 2, p. 89-93.

PEARCE, D.; ROBINSON, R. (2013) Strategic Management; per. from english E. Milyutin, St. Petersburg, Peter, 560.

RUBANOV, M. M. (2013) An early warning system for threats with weak signals. Bulletin of the Khmelnitsky National University, Economic sciences, v. 3, n. 2, p. 257-261.

SHANKRET, A. M.; KARAIM, M. M. (2015) Mechanism of management of economic safety of machine-building enterprise on the basis of weak signals. Scientific notes Ukrainian Academy of Printing, Economic Sciences, n. 1, p. 7-11.

THOMPSON, A. A.; STRICKLAND, A. D. (2013) Strategic Management: Concepts and Situations for Analysis, M.: Williams, 928.

TSARKOV, V. A. (2007) Dynamic models of the economy. Theory and practice of economic dynamics, M.: Economics, p. 212.

ZMOTS, O. I. (2014) Adaptive management of the enterprise on the basis of weak signals. Current problems of the economy, n. 11, p. 462-468.

ZMOTS, O. I. (2012) Peculiarities of Strategic Management of Enterprises Using Weak Signals. Technology audit and production reserves, v. 4, n. 1, p. 41-42.

ZUZAK, R. (2001) Company Early Warning System Conception. Agricultural Economics, v. 47, n. 10, p. 455-458.

ZUZAK, R. (2017) Early warning systems for strategic and crisis management. Access date: http://knowledgeconference.upol.cz/downloads/2017Knowledge_for_Market_Use_Proceedings.pdf, 459-463. 